\section{Alar and Transverse Ligament Calcification and Crown Dens}

\section{To the Editor:}

Takizawa, et al described alar ligament and transverse ligament calcification in patients reported as having rheumatoid arthritis ${ }^{1,2,3}$. Lack of full clinical information precludes assessment as to whether their application of the term "rheumatoid" identifies the specific disease or nonspecifically identifies generalized inflammatory arthritis ${ }^{4}$, considering previous report as a complication of ankylosing spondylitis ${ }^{5}$. In that case, it appeared actually to be a component of ossification of the posterior longitudinal ligament. They attributed the patient's neck pain to this phenomenon, noting similar attribution of previous cases to an inflammatory process.

Takizawa, et al's magnetic resonance imaging and computed tomography images ${ }^{1}$ present a perspective, but perhaps the character of the alar ligament and transverse ligament calcifications/ossifications are even more clearly illustrated by the fossil image in Figure 1. The atlas of Teleoceras USNM (US Smithsonian National Museum of Natural History) 93989, a Late Miocene (dated at more than 5 million yrs) type of rhinoceros ${ }^{6}$ from Frontier County, Nebraska, USA, illustrates alar and transverse ligament calcification. The alar calcification produces a crowned dens appearance.

Because spondyloarthropathy has been documented in $23 \%$ of Teleoceras ${ }^{7,8}$, its pathology may be related to inflammation. Extrapolating from the bellicose character of extant rhinoceros, a traumatic etiology, as suggested by Takizawa, $e t a l^{1}$, for the alar ligament calcification also cannot be ruled out.

BRUCE ROTHSCHILD, MD, Professor of Medicine, Department of Medicine, Northeast Ohio Medical University, Rootstown Township, Ohio; and Department of Vertebrate Paleontology, Carnegie Museum of
Natural History, Pittsburgh, Pennsylvania, USA. Address correspondence to Dr. B. Rothschild, Department of Vertebrate Paleontology, Carnegie Museum, 4400 Forbes Ave., Pittsburgh, Pennsylvania 44272, USA.

E-mail: spondylair@gmail.com

\section{REFERENCES}

1. Takizawa N, Nomura A, Fujita Y. Rare cause of nuchal pain: calcification of the alar ligament. J Rheumatol 2016;43:177-8.

2. Castor WR, Miller JD, Russell AS, Chiu PL, Grace M, Hanson J. Computed tomography of the craniocervical junction in rheumatoid arthritis. J Comput Assist Tomogr 1983;7:31-6.

3. Soubai RB, Tahiri L, Abourazzak FZ, Tizniti S, Harzy T. Calcification of the alar ligament of the cervical spine in a patient with rheumatoid arthritis. Pan Afr Med J 2012;13:41.

4. Rothschild BM. Two faces of "rheumatoid arthritis": Type A versus type B disease. J Clin Rheumatol 1997;3:334-8.

5. Zhang Z, Liu Z, Zhu J. Ossification of the transverse atlantal ligament in ankylosing spondylitis - a case report. Biomed Res 2014;25:617-9.

6. Prothero DR. The evolution of North American rhinoceroses. Cambridge: Cambridge University Press; 2005.

7. Rothschild BM, Prothero DR, Rothschild C. Origins of spondyloarthropathy in Perissodactyla. Clin Exp Rheum 2001;19:628-32.

8. Rothschild BM, Martin LD. Skeletal impact of disease. Albuquerque: New Mexico Museum of Natural History Press; 2006.

J Rheumatol 2016;43:6; doi:10.3899/jrheum.160102

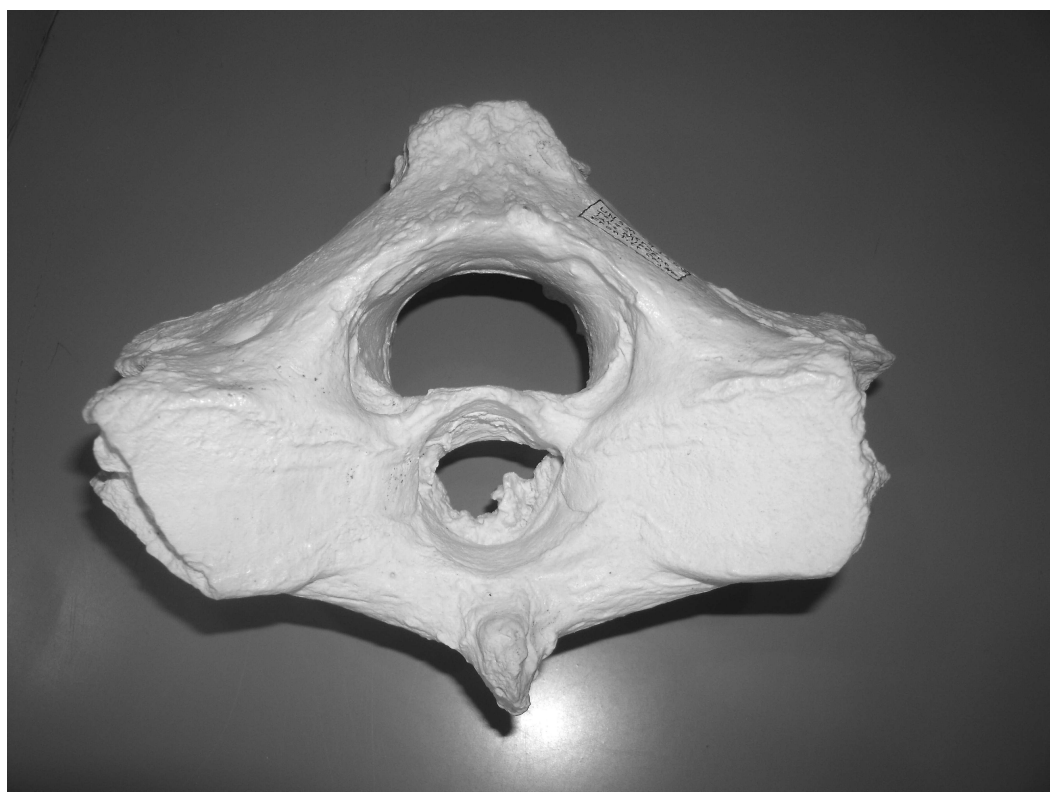

Figure 1. Inferior view of Teleoceras atlas (US Smithsonian National Museum of Natural History, no. 93989). Ossification of transverse ligament. Dens was capped by alar ligament calcification and crowned dens. 